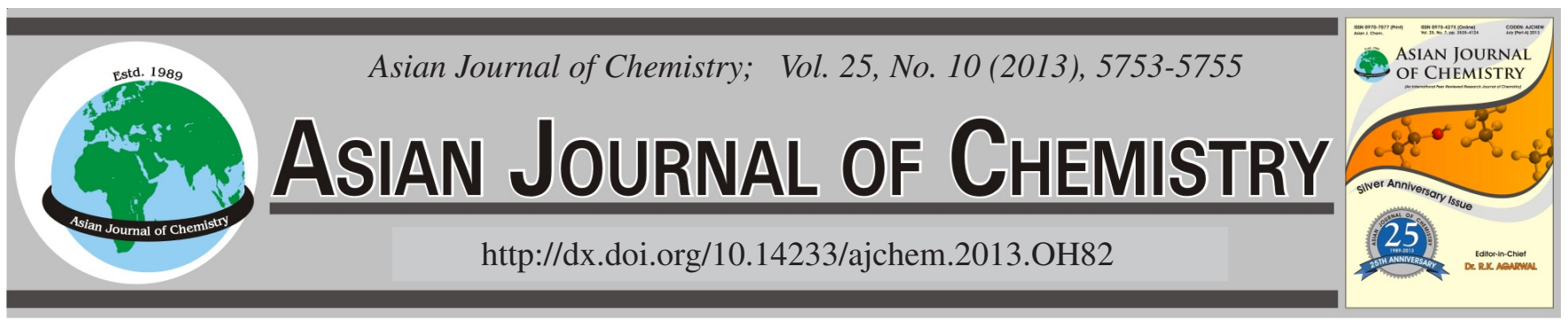

\title{
Microstructure, Piezoelectric and Dielectric Properties of Lead-Free Ceramics $\mathrm{K}_{0.475} \mathrm{Na}_{0.475} \mathrm{Li}_{0.05} \mathrm{NbO}_{3}-\mathrm{CaZrO}_{3}-\mathrm{CuO} \dagger$
}

\author{
Shaobo Li, Qiyi Yin*, Changan Tian, Benhong Yang, Jinsong Xie and Meiling BaO
}

Department of Chemistry and Material Engineering, Hefei University, Hefei 230022, P.R. China

*Corresponding author: E-mail: yinqyi@163.com

AJC-13325

The (1-x) $\mathrm{K}_{0.475} \mathrm{Na}_{0.475} \mathrm{Li}_{0.05} \mathrm{NbO}_{3}-\mathrm{xCaZrO}-2 \%$ molCuO lead-free piezoelectric ceramics have been prepared by conventional technique at $1140{ }^{\circ} \mathrm{C}$ and exhibit highly dense structure by SEM patterns observed. X-ray diffraction analysis shows that the ceramics possess a pure perovskite structure and only have tetragonal phases. The ceramic with $\mathrm{x}=0.045$ possess optimum electrical properties $\left(\mathrm{d}_{33}=176 \mathrm{pC} / \mathrm{N}\right.$, $\mathrm{k}_{\mathrm{p}}=37 \%, \varepsilon_{\mathrm{r}}=1083, \tan \delta=2.4 \%$ ). This results indicate that the ceramic is a promising lead-free piezoelectric ceramic.

Key Words: Lead-free, Microstructure, Dielectric, Piezoelectric, Ceramics.

\section{INTRODUCTION}

Lead-based piezoelectric materials such as $\mathrm{Pb}\left(\mathrm{Zr}\right.$, Ti) $\mathrm{O}_{3}$ (PZT) ceramics are the most widely used, owing to their superior piezoelectric performances ${ }^{1}$. However, the toxicity of lead oxide, which contains more than $60 \mathrm{wt} \%$, can cause damaging to the kidney, brain and nervous system ${ }^{2}$. Thus, many countries have required that all electronic equipment must be lead-free for human health and environmental protection in recent, which results in urgently developing with lead-free piezoelectric ceramics. $\left(\mathrm{K}_{0.5} \mathrm{Na}_{0.5}\right) \mathrm{NbO}_{3}(\mathrm{KNN})$-based ceramics has been paid to a key attention owing to their superior piezoelectric properties, high Curie temperature (about $420^{\circ} \mathrm{C}$ ) and environmental friendliness ${ }^{1-4}$. However, pure KNN ceramic is difficult to densify by conventional sintering technique because of the high volatility of alkaline elements at high sintering temperatures. Considering a better solution to above problems, many studies have been carried out to improve the electrical properties of KNN-based ceramics by forming new solid solutions with other perovskite or perovskite-like $\mathrm{ABO}_{3}$ compounds. such as $\mathrm{KNN}-\mathrm{Bi}\left(\mathrm{Zn}_{0.5} \mathrm{Ti}_{0.5}\right) \mathrm{O}_{3}{ }^{5}, \mathrm{KNN}-\mathrm{LiTaO}_{3}{ }^{6}$, $\mathrm{KNN}-\mathrm{BaTiO}_{3}{ }^{7}$.

In this work, the $(1-\mathrm{x}) \mathrm{K}_{0.475} \mathrm{Na}_{0.475} \mathrm{Li}_{0.05} \mathrm{NbO}_{3{ }^{-}} \mathrm{CaZrO}_{3}-2 \%$ mol CuO lead-free piezoelectric ceramics were fabricated and their structure, dielectric and piezoelectric properties also were investigated. Particularly, we put emphasis on the effect of $\mathrm{CuO}$ additives and substitution $\mathrm{CaZrO}_{3}$ to phase structure and electrical properties of the ceramics.

EXPERIMENTAL

The (1-x) $\mathrm{K}_{0.475} \mathrm{Na}_{0.475} \mathrm{Li}_{0.05} \mathrm{NbO}_{3{ }^{-}{ }_{x}} \mathrm{CaZrO}_{3}$ ( $\mathrm{x}=$ 0.000, 0.025, $0.045,0.065,0.085)$ [KNLN-CZ] ceramics with $2 \% \mathrm{~mol} \mathrm{CuO}$ doping were prepared by the conventional mixed oxide method. $\mathrm{K}_{2} \mathrm{CO}_{3}, \mathrm{Na}_{2} \mathrm{CO}_{3}, \mathrm{Li}_{2} \mathrm{CO}_{3}, \mathrm{CaCO}_{3}, \mathrm{Nb}_{2} \mathrm{O}_{5}$ and $\mathrm{ZrO}_{2}$ were used as starting raw materials. They were ball milled for $16 \mathrm{~h}$ with agate ball media and alcohol. After calcination at $860^{\circ} \mathrm{C}$ for $2 \mathrm{~h}$, the calcined powders were milled again and pressed into disks of 1.2 $\mathrm{cm}$ in diameter and $1 \mathrm{~mm}$ in thickness under $20 \mathrm{MPa}$ using PVA as a binder. The disk samples were sintered at $1140^{\circ} \mathrm{C}$ for $3 \mathrm{~h}$ in air. Silver paste was dried on both sides of the samples at $300{ }^{\circ} \mathrm{C}$ for $5 \mathrm{~h}$ as the electrodes for the electrical measurements. The samples were poled in $120^{\circ} \mathrm{C}$ silicon oil bath by applying a DC electric field of 3-5 kV/mm for $30 \mathrm{~min}$. The electrical properties of all ceramics were measured more than a day later. X-ray diffraction characterization of the ceramics was performed by using $\mathrm{CuK}_{\alpha}$ radiation (Rigaku, Tokyo, Japan). The microstructure of the ceramics was studied by scanning electron microscope (JSM-6700F, Japan). The piezoelectric constant $\mathrm{d}_{33}$ was measured using a piezo- $\mathrm{d}_{33}$ meter (ZJ-3A, China). The electromechanical coupling factor $\mathrm{k}_{\mathrm{p}}$ and mechanical quality factor $\mathrm{Q}_{\mathrm{m}}$ were determined by the resonance method using an impedance analyzer (HP4294A). The dielectric constant and dissipation factor of the ceramics were examined with a LCR analyzer (TH2816).

\section{RESULTS AND DISCUSSION}

Fig. 1 shows X-ray diffraction patterns of the KNLN-CZ ceramics with $2 \% \mathrm{~mol} \mathrm{CuO}$ aids synthesized at $1140{ }^{\circ} \mathrm{C}$ for 
3 h. As shown in Fig. 1(a), it is found that the ceramics show a pure perovskite structure and no secondary phase is detected, suggesting that the dopants were completely diffused into the $\mathrm{K}_{0.475} \mathrm{Na}_{0.475} \mathrm{Li}_{0.05} \mathrm{NbO}_{3}$ lattices, with $\mathrm{Ca}^{2+}$ entering the $\left(\mathrm{K}_{0.475} \mathrm{Na}_{0.475} \mathrm{Li}_{0.05}\right)^{+}$sites as well as $\mathrm{Zr}^{4+}$ occupying the $\mathrm{Nb}^{5+}$ sites, to form a new homogeneous solid solution. It can be seen from Fig. 1(b), the enlarged XRD patterns of the ceramics in the range of $2 \theta$ from $44.5^{\circ}$ to $47.0^{\circ}$ also show that the ceramics only possess the tetragonal phase.
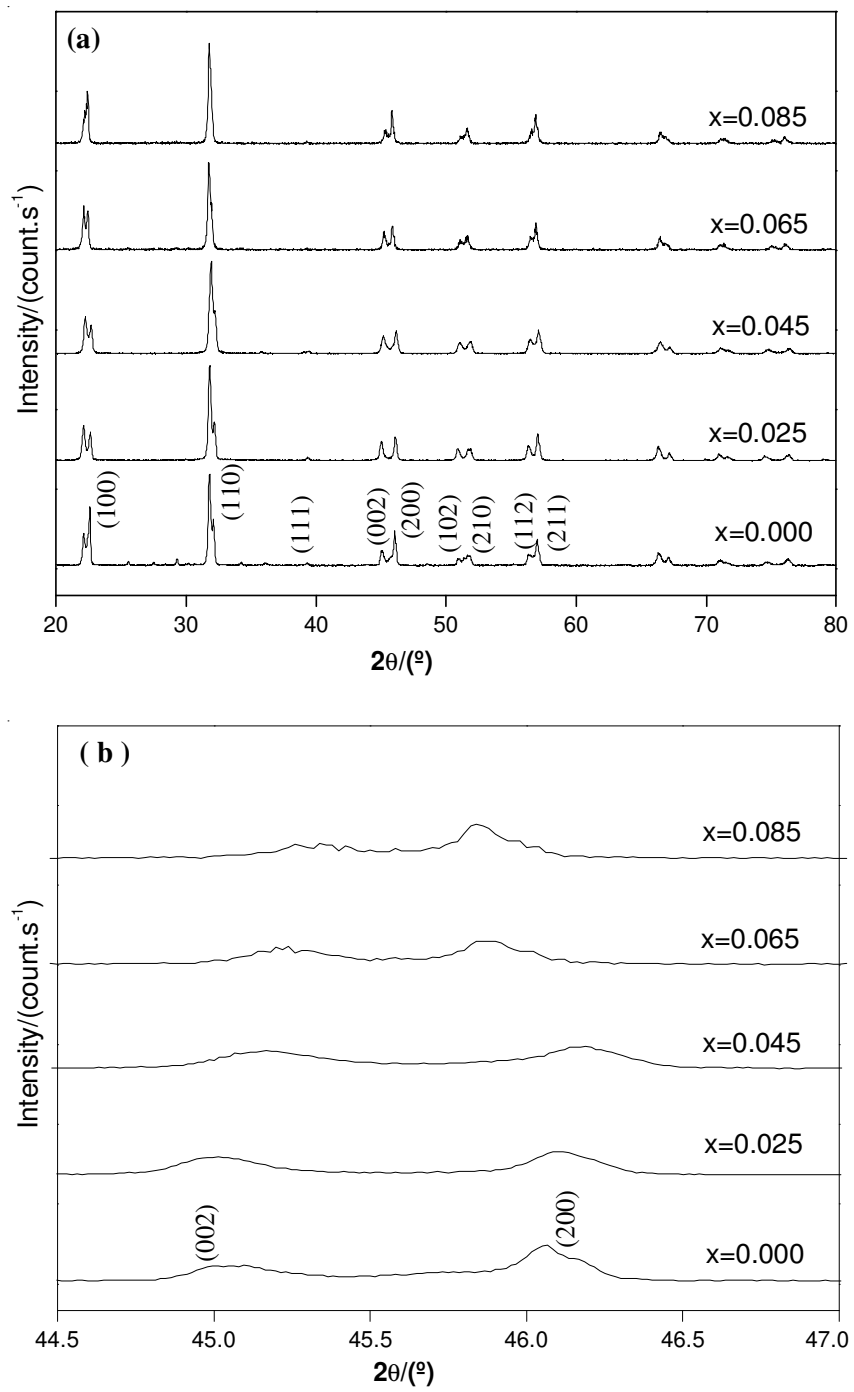

Fig. 1. (a) and (b) XRD patterns of the (1-x) $\mathrm{KNLN}_{-\mathrm{x}} \mathrm{CZ}$ ceramics as a function of $x$

Fig. 2. shows the SEM micrographs of the external and transect of the $(1-\mathrm{x}) \mathrm{KNLN}{ }_{\mathrm{x}} \mathrm{CZ}$ ceramics at $\mathrm{x}=0.045$. As shown in Fig. 2(a), the ceramic has been well-sintered and possess clear grain boundary. Moreover, the ceramic possess relatively high density excepting the nonuniformity of grains and a little of cavitas among grains, which are shown in Fig. 2(b). Obviously, the dopants of $\mathrm{CuO}$ and $\mathrm{CaZrO}_{3}$ are very effective to increase sintering ability and electrical properties of the ceramics.

Fig. 3. shows the $\mathrm{d}_{33}, \mathrm{k}_{\mathrm{p}}, \varepsilon_{\mathrm{r}}$ and $\tan \delta$ of the $(1-\mathrm{x}) \mathrm{KNLN}{ }_{\mathrm{x}} \mathrm{CZ}$ ceramics as a function of $\mathrm{x}$. It can be observed that the properties exhibit a compositional dependence from Fig. 3(a), the piezoelectric constant $d_{33}$ and planar electromechanical coefficient $\mathrm{k}_{\mathrm{p}}$ increased gently with increasing $\mathrm{x}$ and then decreased fastly, giving respectively a maximum value of $176 \mathrm{pC} / \mathrm{N}$ and $37 \%$ at $\mathrm{x}=0.045$. Comparing with $\mathrm{d}_{33}$ and $\mathrm{k}_{\mathrm{p}}$, as shown in Fig. 3(b), the observed er and tand show similar dependences on $\mathrm{x}$, reching a maximum values $\left(\varepsilon_{\mathrm{r}}=1083\right.$ and $\tan \delta=2.4 \%$, respectively) at $x=0.045$. The gradual increasing of electrical properties before maximum values could be included that the ceramics have transformed gradually from a normal ferroelectric to a relaxor ferroelectric. The diffuse phase transition may owing to the increase in the disorder degree of A- and B-site ions after the partial substitutions of $\mathrm{Ca}^{2+}$ for the A-site $\left(\mathrm{K}_{0.475} \mathrm{Na}_{0.475} \mathrm{Li}_{0.05}\right)^{+}$and $\mathrm{Zr}^{4+}$ for the $\mathrm{B}$ - site $\mathrm{Nb}^{5+}$. After maximum values, decreased properties due to increasing difficulties in ferroelectric domain inversion.
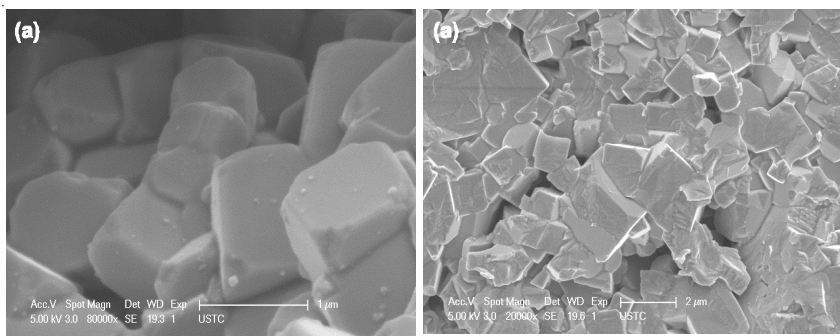

Fig. 2. SEM micrographs of the $(1-\mathrm{x}) \mathrm{KNLN}_{\mathrm{x}} \mathrm{CZ}(\mathrm{x}=0.045)$ ceramic (a) external; (b) transect
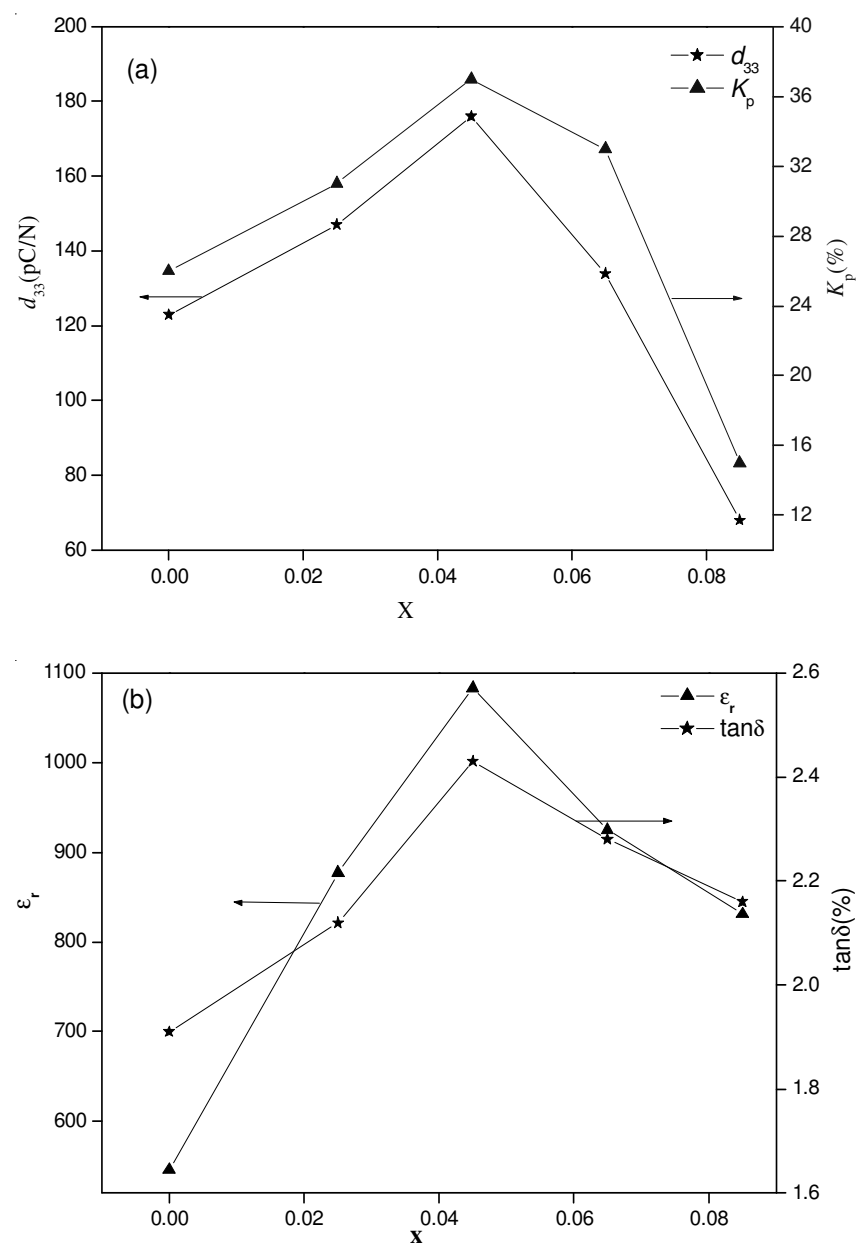

Fig. 3. (a) and (b) Variations of $\mathrm{d}_{33}, \mathrm{k}_{\mathrm{p}}, \varepsilon_{\mathrm{r}}$ and tand with $\mathrm{x}$ for the (1-x)KNLN-x${ }_{-\mathrm{CZ}}$ ceramics 


\section{Conclusion}

In this study, the (1-x) $\mathrm{K}_{0.475} \mathrm{Na}_{0.475} \mathrm{Li}_{0.05} \mathrm{NbO}_{3{ }^{-} \mathrm{x}} \mathrm{CaZrO}_{3}-2 \%$ mol CuO lead-free piezoelectric ceramics have been prepared by the conventional ceramics sintering technique at $1140{ }^{\circ} \mathrm{C}$ and show highly density by SEM analysing. X-ray diffraction analysis shows that the ceramics possess a pure perovskite structure and only have tetragonal phases. The ceramic with $\mathrm{x}$ $=0.045$ exhibits optimum electrical properties $\left(\mathrm{d}_{33}=176 \mathrm{pC} / \mathrm{N}\right.$, $\left.\mathrm{k}_{\mathrm{p}}=37 \%, \varepsilon_{\mathrm{r}}=1083, \tan \delta=2.4 \%\right)$. These results indicate the dopants of $\mathrm{CuO}$ and $\mathrm{CaZrO}_{3}$ are very effective way to increase sintering ability and electrical properties of the ceramics.

\section{ACKNOWLEDGEMENTS}

This work was supported by the National Nature Science Foundation of China (No. 51272001, 51072001, 51102073), the Natural Science Foundation of Anhui Province of China (No.10040606Q53, 1308085QB35, 1208085MB24), the Natural Science Foundation of Education Department of Anhui Province
(No. KJ2013B229, KJ2012B154, KJ2010B148), the Laboratory of Environmental Material and Environmental Engineering of JiangSu Province in China (No. K11031) and the College Students' Innovation and Entrepreneurship Training Program of China (No. 201211059005, 201211059006, 201211059007, 201211059009, 201211059011), and the Teaching Research Projects of Hefei University (No.2012jyxm48).

\section{REFERENCES}

1. G.H. Haertling, J. Am. Ceram. Soc., 50, 329 (1967).

2. M.D. Maeder, D. Damjanovic and N. Setter, J. Electroceram., 13, 385 (2004).

3. L. Egerton and C.A. Bieling, Ceramic. Bull., 47, 1151 (1968).

4. Y. Saito, H. Takao, T. Tani, T. Nonoyama, K. Takatori, T. Homma, T. Nagaya and M. Nakamura, Nature, 432, 84 (2004).

5. M. Sutapun, C.C. Huang, D.P. Cann and N. Vittayakorn, J. Alloys Comp., 479, 462 (2009).

6. Y.J. Dai, X.W. Zhang and G.Y. Zhou, Appl. Phys. Lett., 90, 262903 (2007).

7. H.Y. Park, C.W. Ahn and H.J. Lee, Appl. Phys. Lett., 89, 062906 (2006). 